ISSN 0103-8478

\title{
Incompatibilidade de enxertia em Prunus
}

\author{
Graft incompatibility in Prunus
}

\author{
Ivan dos Santos Pereira ${ }^{\mathrm{I}}$ José Carlos Fachinello ${ }^{\mathrm{II}}$ Luis Eduardo Corrêa Antunes ${ }^{\mathrm{III}}$ \\ Ângela Diniz Campos ${ }^{\mathrm{IV}}$ Ana Pina ${ }^{\mathrm{V}}$
}

\section{- REVISÃO BIBLIOGRÁFICA -}

\section{RESUMO}

A incompatibilidade de enxertia é um problema que, além de prejuízo econômico aos produtores, causa atraso no lançamento de novas cultivares-copa e portaenxertos, devido ao longo período de tempo necessário para os testes de compatibilidade. O objetivo desta revisão é fazer um apanhado das principais e mais relevantes pesquisas realizadas envolvendo o tema incompatibilidade de enxertia em espécies frutíferas, especialmente as do gênero Prunus. Incompatibilidade é um fenômeno extremamente complexo, que envolve interações anatômicas, fisiológicas, bioquímicas e moleculares entre a cultivar-copa e o portaenxerto. Sendo, por essa razão, um problema de difícil estudo. Porém, acredita-se que através de uma análise conjunta dos diversos mecanismos de incompatibilidade, se pode avançar mais rapidamente no entendimento deste fenômeno.

Palavras-chave: enxertia, compatibilidade, hormônios, fenóis, prunasina.

\section{ABSTRACT}

The graft incompatibility is a problem that causes economic loss to producers and delay in the launch of new cultivars and rootstock because of the long time required for compatibility testing. The aim of this review is to show of the most important and relevant research conducted over the years involving the graft incompatibility in fruit species, specially the genus Prunus. The graft incompatibility is an extremely complex phenomenon that involves anatomical, physiological, biochemical and molecular interactions between scion and rootstock. Being for this reason a difficult problem to analyze. However, it is believed that through a joint analysis of graft incompatibility the understanding of the mechanisms may advance more quickly and so allow the solution for the phenomenon.

Key words: grafting, compatibility, hormones, phenols, prunasin.

\section{INTRODUÇÃO}

A enxertia é uma técnica de propagação assexuada, através da qual são unidos dois indivídos, cultivar-copa e portaenxerto, com o objetivo de formar uma nova planta, o enxerto. Com a enxertia, agregam-se características de interesse de ambos os genótipos, visando, em geral, à adaptação edafoclimática, incrementos de produção e melhoria da qualidade dos frutos (ORAZEM et al., 2011; FORCADA et al., 2012; PEREIRA, 2012; HUSSAIN et al., 2013). Em alguns casos, pode-se ter, ainda, um terceiro componente chamado filtro ou interenxerto, que faz uma espécie de ponte entre portaenxerto e cultivar-copa, visando, na maior parte das vezes, tornar a combinação compatível (TELLES et al., 2009; YUAN et al., 2011).

O processo de pegamento de um enxerto envolve três etapas principais, a proliferação de calo com estabelecimento de contato entre as regiões cambiais da cultivar-copa e do portaenxerto, a diferenciação de células parenquimáticas de calo em novas células cambiais, que conectam os câmbios da cultivar-copa e do portaenxerto, e a formação de novos floema e xilema (ERREA,1998; HARTMANN et al., 2010; PINA et al., 2012). Alguns autores consideram que o primeiro evento pode ocorrer tanto em combinações compatíveis quanto incompatíveis.

\footnotetext{
IPrograma de Pós-doutorado CAPES-Embrapa, Embrapa Clima Temperado, 96010-971, Pelotas, RS, Brasil. E-mail: ivanspereira@gmail.com. Autor para correspondência.

IIDepartamento de Fitotecnia, Universidade Federal de Pelotas (UFPEL), Pelotas, RS, Brasil

IIIDepartamento de Fruticultura, Embrapa Clima Temperado, Pelotas, RS, Brasil.

${ }^{\mathrm{IV}}$ Laboratório de Fisiologia Vegetal, Embrapa Clima Temperado, Pelotas, RS, Brasil.

VUnidad de Fruticultura, Centro de Investigación y Tecnología Agroalimentaria de Aragón (CITA), Zaragoza, Espanha. Recebido 08.08.13 Aprovado 26.02.14 Devolvido pelo autor 22.06.14 CR-2013-1074.R1
} 
Por outro lado, a formação de xilema e floema é apontada como fundamental para o sucesso da enxertia (HARTMANN et al., 2010; PINA et al., 2012).

Acultivar-copa e o portaenxerto geralmente pertencem à mesma espécie ou a espécies muito próximas dentro de um gênero botânico (ZARROUK et al., 2010). No entanto, a evolução da fruticultura e o seu crescimento em importância na economia mundial fez com que essa atividade se propagasse por regiões marginais. Situação que provocou o surgimento de problemas de adaptação, que, por sua vez, resultam em produtividade insatisfatória e frutos de baixa qualidade. A partir destes problemas, passou a ser mais frequente a enxertia entre genótipos cada vez mais distintos taxonomicamente, com o objetivo de buscar-se uma forma de superar tais dificuldades (DARIKOVA et al., 2011; PEREIRA, 2012).

Combinações interespecíficas podem trazer inúmeros benefícios ao sistema de produção. Mas, a combinação de indivíduos geneticamente diferentes muitas vezes resulta em um problema grave e complexo, a incompatibilidade de enxertia (TELLES et al., 2009; HARTMANN et al., 2010; DARIKOVA et al., 2011; PEREIRA, 2012; PINA et al., 2012). A incompatibilidade de enxertia é o desenvolvimento anormal do enxerto, em razão de diferenças anatômicas, fisiológicas, bioquímicas e moleculares ainda desconhecidas, resultando em prejuízo visível ou não à união do enxerto, além de crescimento vegetativo retardado, baixa produtividade e em casos severos, a morte da planta. Este fenômeno pode ser observado em diferentes níveis, conforme os genótipos enxertados. Em casos brandos, nota-se apenas a redução do vigor, podendo ser até um efeito desejável, já que favorece a produção de frutos em detrimento do crescimento vegetativo, sendo conhecido em alguns casos como efeito ananizante (MARTÍNEZ-BALLESTA et al., 2010; DARIKOVA et al., 2011; TOMBESI et al., 2011; GJAMOVSKI \& KIPRIJANOVSKI, 2011). Porém, em casos de incompatibilidade aguda, a cultivar-copa e o portaenxerto nem sequer chegam a unir-se, ou, em casos em que ocorre essa união, o enxerto definha e morre ainda nos primeiros meses após a enxertia (RODRIGUES et al., 2002; PINA et al., 2009; HARTMANN et al., 2010).

Os sintomas de incompatibilidade em espécies lenhosas incluem espessamento da casca na região de união, folhas cloróticas, queda prematura de folhas, atraso na brotação, diferenças de vigor entre portaenxerto e cultivar-copa, engrossamento excessivo do caule abaixo, acima ou no ponto de união do enxerto, rompimento da união do enxerto, redução do crescimento vegetativo, baixa produtividade e morte prematura das plantas (HARTMANN et al., 2010; ZARROUK et al., 2010).

O objetivo desta revisão é realizar um apanhado das principais e mais relevantes pesquisas realizadas ao longo do tempo, envolvendo o tema incompatibilidade de enxertia. Busca-se ainda, abordar os principais mecanismos de incompatibilidade estudados atualmente, analisando as complexas interações entre cultivar-copa e portaenxerto.

Tipos de incompatibilidade de enxertia

Ao longo dos anos, foram propostas várias formas de classificar a incompatibilidade de enxertia. HERRERO (1956) propôs quatro classes de incompatibilidade: a) falha no pegamento do enxerto ou incompatibilidade total; b) falha do enxerto devido à infecção por vírus em um dos componentes do enxerto; c) obstrução mecânica da união do enxerto; e d) estrutura anormal da união, geralmente, associada ao acúmulo de amido. Já SCARAMUZZI (1959) dividiu a incompatibilidade em três grupos baseados na resposta do enxerto a um terceiro componente, um interenxerto. No primeiro grupo, a incompatibilidade entre as partes é superada pela utilização de um interenxerto compatível com ambos; no segundo, o interenxerto não é capaz de prevenir a incompatibilidade; e, no terceiro, o interenxerto induz à incompatibilidade entre genótipos compatíveis. Porém, esse tipo de classificação ficou restrito apenas às combinações nas quais se utiliza um interenxerto. No entanto, entre as classificações já propostas, a de MOSSE (1962) é a mais utilizada atualmente. Nesta classificação, os autores dividem a incompatibilidade de enxertia em dois tipos: 'translocada' e 'localizada'.

\section{Incompatibilidade 'translocada'}

Esse tipo de incompatibilidade se caracteriza por apresentar sintomas visíveis durante o desenvolvimento das plantas, como parada precoce no crescimento, folhas cloróticas evoluindo para avermelhadas, queda prematura das folhas, redução do ritmo de crescimento radicular, redução da translocação de carboidratos na região de união, havendo acúmulo na cultivar-copa (MOING et al., 1987; MORENO et al., 1993; ZARROUK et al., 2010).

Embora não se tenha conhecimento da causa, alguns autores acreditam que esse bloqueio da translocação seja provocado pela redução do número de células e elementos do floema na união do enxerto (ALONI et al., 2008; PINA \& ERREA, 2009; MARTÍNEZ-BALLESTA et al., 2010). Ocorre também a produção, pelas folhas, de compostos 
tóxicos, como o cianeto, que causa a degeneração dos tecidos do portaenxerto, dificultando o estabelecimento de conexões vasculares funcionais (MOORE, 1986; NOCITO et al., 2010; DARIKOVA et al., 2011). Esse tipo de incompatibilidade, em geral, não pode ser evitado pela utilização de um interenxerto. Um exemplo clássico desse tipo de incompatibilidade pode ser observado entre cultivares de pessegueiro enxertado sobre portaenxertos de ameixeira (MORENO et al., 1993).

Atualmente, a medida dos valores SPAD (Soil Plant Analysis Diagnostic) e/ou a análise da concentração de clorofila das folhas permite identificar casos severos de incompatibilidade deste tipo, entre cultivares-copa e portaenxertos de Prunus (ZARROUK et al., 2010).

Incompatibilidade 'localizada'

A incompatibilidade 'localizada' pode ser definida como a ausência de desenvolvimento normal dos tecidos no ponto de enxertia, resultando em feixes vasculares não completamente lignificados, que provocam uma interrupção da continuidade vascular e cambial, com consequentes problemas físicos na união do enxerto (MOSSE, 1958). Está associada a uma má formação estrutural do ponto de união, podendo resultar em ruptura do enxerto (PINA \& ERREA, 2009; PINA et al., 2009; PEREIRA, 2012), devido à necrose do tecido cambial ou da ausência de diferenciação do tecido vascular na linha de união do enxerto. Plantas com esse tipo de incompatibilidade apresentam desenvolvimento lento, proporcional ao grau de descontinuidade da união (ERMEL et al., 1999; HARTMANN, et al., 2010). Os sintomas externos são pouco evidentes, podendo tardar vários anos para que sejam identificados (PINA \& ERREA, 2008). Em estágios avançados, há esgotamento do sistema radicular devido à translocação deficiente no ponto de união (ZARROUK et al., 2010). Normalmente, a incompatibilidade 'localizada' pode ser superada pela adoção de um interenxerto compatível a ambas as partes.

Diferentes estudos têm indicado a implicação de compostos fenólicos na diferenciação celular e na falta de lignificação em uniões incompatíveis deste tipo (NOCITO et al., 2010; ZARROUK et al., 2010; PINA et al., 2012; PEREIRA et al., 2013). Outros compostos associados ao problema são os glicosídeos cianogênicos amigdalina e prunasina. O acúmulo de cianeto liberado pela hidrólise destes compostos na união do enxerto pode causar necrose das células cambiais e descontinuidade vascular (NOCITO et al., 2010; PEREIRA, 2012).
Embora a classificação proposta por MOSSE (1958) seja a mais aceita e utilizada, está baseada exclusivamente em sintomas e não considera as causas. Dessa forma, como os sintomas são, muitas vezes, similares em ambos os tipos, é difícil uma classificação precisa. Acredita-se que, a partir do momento em que os mecanismos pelos quais a incompatibilidade se expressa sejam compreendidos completamente, essa classificação possa ser alterada e se passe a levar em conta principalmente a causa.

Mecanismos da incompatibilidade de enxertia

Os eventos envolvidos na enxertia são conhecidos, no entanto, os mecanismos pelos quais a incompatibilidade se expressa, nas diferentes combinações, não estão claros. Várias hipóteses têm sido estudadas na tentativa de explicar esse fenômeno. Um dos grandes problemas é o grande número de combinações interespecíficas, que implica uma série de interações estruturais, bioquímicas e fisiológicas (PINA et al., 2012).

Nesta revisão, são abordados os mecanismos mais estudados e que apresentam o embasamento mais coerente, sendo eles: o reconhecimento celular promovido pelas plasmodesmas, as interações hormonais, as diferenças quantitativas e/ou qualitativas dos compostos fenólicos e a incompatibilidade causada pelos glicosídeos cianogênicos.

\section{Plasmodesmas e o reconhecimento celular}

Estudos anatômicos realizados em enxertos incompatíveis demonstram que, em poucas semanas após a enxertia, já se pode observar a formação de conexões vasculares problemáticas, com descontinuidade vascular e degeneração do floema na área de união (PINA \& ERREA, 2005; PINA et al., 2009), resultando em distúrbio no transporte de fotoassimilados entre os componentes do enxerto (DARIKOVA et al., 2011).

As plasmodesmas são extensões tubulares da membrana plasmática que atravessam a parede celular e conectam o citoplasma de células adjacentes, permitindo a comunicação celular (PINA et al., 2009; PINA et al., 2012). Dessa forma, desempenham um importante papel no mecanismo de comunicação celular necessário no processo de enxertia (PINA \& ERREA, 2005; PINA et al., 2009). O contato entre as células da cultivar-copa e do portaenxerto, estabelecido pelas plasmodesmas, resulta em uma conexão simplástica que permite a interação metabólica mútua entre ambos (PINA \& ERREA, 2005; PINA \& ERREA, 2009; PINA et al., 2009). As pesquisas de KOLLMANN et al. (1995) sobre o mecanismo de formação das plasmodesmas 
mostraram o desenvolvimento de plasmodesmas interespecíficas entre cultivar-copa e portaenxerto, sugerindo que o reconhecimento celular e a coordenação funcional têm importante papel na formação do enxerto. Nesse sentido, PINA \& ERREA (2005) indicam que a ocorrência de plasmodesmas não funcionais pode estar associada à incompatibilidade de enxertia entre espécies de Prunus. Fato que foi comprovado anos mais tarde, quando PINA et al. (2009) demonstraram que o acoplamento plasmodesmatal insuficiente, numa fase inicial de desenvolvimento do enxerto, pode resultar em incompatibilidade de enxertia. Recentemente, estudos de PINA et al. (2012), com diferentes combinações de Prunus, demonstraram que a proliferação e a aderência do calo ocorrem em ambas às combinações, compatíveis e incompatíveis, uma semana após a enxertia. Porém, a formação do novo câmbio, derivado do tecido de calo, parece ser atrasada em heteroenxertos ou enxertos interespecíficos, quando comparado a homoenxertos ou enxertos intraespecíficos. Analisando o acoplamento plasmodesmal, principalmente dentro dos tecidos envolvidos no processo de enxerto, os mesmos autores verificaram ainda que o acoplamento foi significativamente mais elevado na interface de combinações compatíveis. Essas novas descobertas reforçam a ideia de que as células do calo estão desempenhando papel central na interação entre cultivarcopa e portaenxerto e que a rejeição finalé predeterminada já nas etapas iniciais da formação do enxerto.

\section{Hormônios}

Os fitohormonios desempenham papel importante sobre as interações entre cultivar-copa e portaenxerto, além de auxiliarem na sinalização do processo de formação da união e na comunicação entre os componentes do enxerto (ALONI et al., 2010).

Tem sido relatado que a compatibilidade entre cultivar e portaenxerto é afetada pelos hormônios de crescimento (MARTÍNEZ-BALLESTA et al., 2010; ALONI et al., 2010). Em especial, a auxina tem sido associada a estágios importantes do processo de formação do enxerto, como a proliferação e diferenciação do calo (MOGHADAM et al., 2012), sugerindo que o seu acúmulo na base da cultivarcopa esteja altamente relacionada com o sucesso da enxertia. Entretanto, uma das hipóteses para a incompatibilidade de enxertia é de que a auxina é transportada em taxas diferentes da cultivar-copa para o portaenxerto, afetando a produção de citocinina nas raízes e provocando taxas de crescimento diferencial entre portaenxerto e cultivar-copa (DARIKOVA et al., 2011). Por outro lado, ALONI et al. (2008) sugerem que a causa pode ser a ocorrência de desequilíbrio hormonal no sistema radicular, principalmente com relação à auxina e etileno. Segundo esses autores, após a enxertia, quando as conexões vasculares estão sendo estabelecidas, a auxina produzida na cultivar é translocada para o sistema radicular, onde atinge concentrações muito elevadas, que desencadeiam um processo de degradação e deterioração das raízes. Estudos convergentes ainda sugerem que os níveis elevados de auxina podem ser causados por uma síntese elevada de etileno (ALONI et al., 2010; MUDAY et al., 2012), hormônio que estimula, através de sua via de sinalização, a biossíntese de auxina em diferentes órgãos da planta, além, de aumentar a capacidade de transporte de auxina, pois regula a transcrição dos seus componentes de transporte, como AUX1 e PIN2 (IVANCHENKO et al., 2008; ALONI et al., 2010; MUDAY et al., 2012). O etileno pode ainda induzir estresse oxidativo pela produção de células reativas de oxigênio (ALONI et al., 2010; HURR et al., 2013), provocando crescimento reduzido e problemas de compatibilidade (MOGHADAM et al., 2012).

\section{Compostos fenólicos}

Os compostos fenólicos são um grupo de produtos do metebolismo secundário das plantas com uma grande diversidade de funções (ERREA, 1998; SINGH et al., 2012). Desempenham papel importante no processo de enxertia, pois, participam da estrutura das plantas e estão envolvidos em um grande número de rotas metabólicas, bem como na resposta das plantas ao ambiente e na interação entre cultivar-copa/ portaenxerto (RODRIGUES et al., 2002; TELLES et al., 2009; PINA et al., 2012).

Inúmeros autores têm relacionado à incompatibilidade de enxertia com diferenças quantitativas e/ou qualitativas no conteúdo de fenóis, além de mudanças na atividade das enzimas que regulam a síntese desses compostos (ERREA, 1998; RODRIGUES et al., 2002; MNG'OMBA et al., 2008; PINA \& ERREA, 2008; TELLES et al., 2009; ZARROUK et al., 2010; YUAN et al., 2011; PINA et al., 2012; PEREIRA et al., 2013). Segundo ERREA (1998), os compostos fenólicos estão implicados em todos os eventos envolvidos no processo de enxertia. $\mathrm{O}$ autor demonstra que uma situação de estresse contínuo, causado pela falta de adaptação das duas partes que formam o enxerto, pode desencadear uma série de eventos, resultando em anormalidades no desenvolvimento deste. Mudanças que afetam a difusão e a circulação de fenóis podem estar envolvidas em dano celular e alteração do sistema cambial na união do enxerto. Além disso, um forte acúmulo de fenóis pode levar a sua oxidação com 
ação tóxica sobre uma série de reações metabólicas, inclusive a síntese de lignina, composto essencial para o sucesso da enxertia (ERREA, 1998).

Compostos fenólicos como ligninas, flavonoides e antocianinas são produzidos a partir da vía fenilpropanoide, cujos produtos têm sido relacionados com a resposta a muitos tipos de estresse, consistindo em importante fonte de pesquisa sobre o fenômeno da incompatibilidade de enxertia. Estudos recentes de expressão gênica apontam para o envolvimento de ezimas chave da vía fenilpropanoide, como a fenilalanina amônialiase (PAL), a cianamato 4-hidroxilase $(\mathrm{C} 4 \mathrm{H})$ e a 4-cumarato Coa-ligase (4CL), no mecanismo de incompatibilidade entre espécies de Prunus (PINA \& ERREA, 2008, PEREIRA, 2012; PINA et al., 2012; PEREIRA et al., 2013). Os resultados desses estudos indicam que, além de alterações anatômicas, fisiológicas e bioquímicas, mudanças moleculares também estão envolvidas no fenômeno. Em geral, os autores desses estudos observaram que há uma maior expressão destas enzimas, associado a uma elevada produção de diversos tipos de fenóis em combinações incompatíveis de Prunus, corroborando outros trabalhos, nos quais foram observadas diferenças quantitativas e qualitativas entre o perfil de fenóis de combinações compatíveis e incompatíveis (ERREA, 1998; MNG'OMBA et al., 2008; TELLES et al., 2009; ZARROUK, et al., 2010). Entretanto, segundo PEREIRA (2012), o aumento na biossíntese de compostos fenólicos, observado em combinações incompatíveis, ocorre em resposta ao estresse oxidativo causado pelo acúmulo de espécies reativas de oxigênio (ROS), provocado pela incompatibilidade de enxertia que possui outra causa principal, que, em alguns casos, pode ser a cianogênese diferencial entre cultivar-copa e portaenxeto.

Glicosídeos cianogênicos (GCs)

Os glicosídeos cianogênicos (GCs) prunasina e amigdalina estão presentes em muitos tipos de tecidos, como raízes, caules, brotos, folhas e frutos, especialmente em espécies da família Rosacea (VETTER, 2000; GANJEWALA et al., 2010; PEREIRA, 2012; SÁNCHEZ-PÉREZ et al., 2012). Compostos do metabolismo secundário, que são indicados por muitos autores como responsáveis pela incompatibilidade de enxertia (MOORE, 1986; NOCITO et al., 2010; PEREIRA, 2012). Em combinações incompatíveis de pessegueiro com amendoeira, a prunasina está presente tanto na cultivar quanto no portaenxerto, porém, em concentração significativamente inferior na amendoeira (GUR \&
BLUM, 1973). Nesse caso, ocorre a translocação de prunasina da cultivar (pessegueiro) para o portaenxerto (amendoeira), onde é hidrolisado e há a liberação cianeto. No caso das combinações entre pereira e marmeleiro, a prunasina, que ocorre no marmeleiro e não na pereira, ascende do portaenxerto para a cultivarcopa, onde é hidrolisado pela $\beta$-glicosidase, ocorrendo a liberação de cianeto na interface do enxerto (MOORE, 1986; NOCITO et al., 2010).

Pelo fato dos GCs e da $\beta$-glicosidase encontrarem-se compartimentados, o processo de cianogênese inicia apenas quando ocorre o rompimento destes compartimentos, fato que provavelmente ocorre durante o processo de enxertia. Uma vez em contato com a amigdalina, a enzima o hidrolisa, gerando uma molécula de glicose e outra de prunasina. Posteriormente, a prunasina é hidrolisada pela mesma enzima, produzindo outra molécula de glicose e uma $\alpha$-hidroxilitrila, que finalmente sofre ação de uma hidroxilitrila-liase, resultando na liberação do cianeto (GUR \& BLUM, 1973; GANJEWALA et al., 2010; NOCITO et al., 2010). O cianeto liberado na união do enxerto causa prejuízo à atividade cambial e necrose das células na interface do enxerto, afetando o sistema vascular e dificultando a translocação através da união do enxerto (MOORE, 1986). Segundo NOCITO et al. (2010), a incompatibilidade causada pelos GCs se origina de um distúrbio que estes compostos provocam na cadeia respiratória do enxerto. $\mathrm{O}$ cianeto, liberado pela hidrólise dos GCs, interrompe a cadeia respiratória prejudicando a respiração e fazendo com que as células vegetais ativem uma via alternativa, que é composta pela oxidase alternativa (AOX). $\mathrm{O}$ aumento no consumo de $\mathrm{O}_{2}$ observado em combinações incompatíveis se deve a um incremento do fluxo de elétrons ao longo da via de respiração mitocondrial alternativa (NOCITO et al., 2010). Este comportamento tem sido amplamente relacionado a diferentes formas de estresses em tecidos vegetais e resulta em dano oxidativo secundário, devido ao acúmulo de espécies reativas de oxigênio (ROS), como o peróxido de hidrogênio $\left(\mathrm{H}_{2} \mathrm{O}_{2}\right)$ (CARNEIRO et al., 2012; WANG et al., 2012). As ROS têm potencial de interagir com muitos componentes celulares e a sua alta concentração gera estresse oxidativo, podendo levar à morte celular, que, quando ocorre, se caracteriza por necrose dos tecidos (GAO et al., 2008; MULLINEAUX \& BAKER, 2010; IAKIMOVA et al., 2013), sintoma comum na região de união de combinações incompatíveis.

Em geral, as espécies cianogênicas apresentam a capacidade de metabolizar o 
cianeto, evitando danos celulares. O processo de desintoxicação do cianeto é composto por duas rotas principais, a primeira envolve a formação de $\beta$-cianoalanina a partir do cianeto e da cisteína, reação catalisada pela $\beta$-cianoalanina sintase, que é posteriormente convertida em asparagina (YI et al., 2012). A segunda rota converte o cianeto em tiocianato e é catalisada pela rodanase (GANJEWALA et al., 2010). Dessa forma, tanto a manifestação quanto o grau da incompatibilidade podem depender também da capacidade de desintoxicação da planta.

Baseado nas informações relatadas neste trabalho em relação ao mecanismo de incompatibilidade por cianogênese, a avaliação dos níveis de GCs em cultivares-copa e portaenxertos pode ser empregado como um importante indicador de compatibilidade. Ou seja, genótipos com concentração de GCs, especialmente de prunasina, muito distintos, provavelmente, apresentarão algum nível de incompatibilidade ao serem enxertados.

Pesquisas futuras

Atualmente, com o sequenciamento do genoma do pessegueiro e outras espécies de Prunus (Genome Database for Rosaceae - GDR - http://www. rosaceae.org/), espera-se avançar mais rapidamente em direção ao entendimento do fenômeno de incompatibilidade de enxertia. A partir dessas informações, está sendo possível tratar esse tema de forma mais minuciosa, uma vez que se podem comparar os perfis de expressão de genes envolvidos nos diversos mecanismos de incompatibilidade, em combinações compatíveis e incompatíveis, determinando-se a verdadeira função de cada um dentro da complexa cadeia de interações que ocorrem entre cultivar-copa e portaenxerto. Inclusive, ao se identificar genes que possam estar causando a falta de compatibilidade, será possível um trabalho de silenciamento destes genes, possibilitando a enxertia entre genótipos até então incompatíveis.

\section{CONCLUSÃO}

Conforme foi apresentado e discutido no presente trabalho, a incompatibilidade é um fenômeno complexo, que envolve inúmeras formas de interação da cultivar-copa com o portaenxerto e, por isso, de difícil estudo. Essa complexidade do problema contribuiu para que, por muitos anos, os estudos fossem focados em mecanismos isolados. Entretanto, com a evolução da biotecnologia, as pesquisas precisam evoluir de forma que se busque compreender possíveis interações entre eles, assim como entender prováveis relações de causa e efeito entre os mecanismos de incompatibilidade estudados, buscando mitiga-los. Um dos principais objetivos dos pesquisadores que trabalham com esse tema atualmente é, além de compreendê-lo completamente, encontrar um marcador que possibilite prever se uma determinada combinação será ou não compatível e, desta forma, reduzir a necessidade de longos testes a campo, com redução de custos e tempo.

\section{AGRADECIMENTOS}

Os autores agradecem a Coordenação de Aperfeiçoamento de Pessoal de Nível Superior (CAPES) e ao Conselho Nacional de Desenvolvimento Científico e Tecnológico (CNPq) pelas bolsas de estudos consedidas.

\section{REFERÊNCIAS}

ALONI, B. et al. Hormonal signaling in rootstock-scion interactions. Scientia Horticulturae, v.127, n.2, p.119-126, 2010. Disponível em: <http:/www.sciencedirect.com/science/article/pii/ S1360138512000295>. Acesso em: 10 nov. 2011. doi: 10.1016/j. bbr.2011.03.031.

ALONI, B. et al. Physiological and biochemical changes at the rootstock-scion interface in graft combinations between Cucurbita rootstocks and a melon scion. Journal of Horticultural Science \& Biotechnology, v.83, p.777-783, 2008. Disponível em: <http:// www.jhortscib.org/Vol83/83_6/17.htm>. Acesso em: 10 nov. 2011.

CARNEIRO, P. et al. Disruption of alternative NAD(P) $\mathrm{H}$ dehydrogenases leads to decreased mitochondrial ROS in Neurospora crassa. Free Radical Biology and Medicine, v.52, n.2, p.402-409, 2012. Disponível em: $<$ http://dx.doi.org/10.1016/j. freeradbiomed.2011.10.492>. Acesso em: 02 jan. 2013. doi: 10.1016/j.freeradbiomed.2011.10.492.

DARIKOVA, J.A. et al. Grafts of woody plants and the problem of incompatibility between scion and rootstock (a review). Journal of Siberian Federal University, v.4, n.1, p.54-63, 2011. Disponível em: <http://elib.sfu-kras.ru/bitstream/2311/2376/1/Darikova.pdf>. Acesso em: 02 dez. 2012.

ERMEL, F.F. et al. Localized graft incompatibility in pear/quince (Pyrus communis/Cydonia oblonga) combinations: multivariate analysis of histological data from 5-month-old grafts. Tree Physiology, v.19 n.10, p.645-654, 1999. Acesso em: 10 dez. 2010. doi: 10.1093/treephys/19.10.645.

ERREA, P. Implications of phenolic compounds in graft incompatibility in fruit tree species. Scientia Horticulturae, v74, p.195-205, 1998. Disponível em: <http:/www.sciencedirect.com/ science/article/pii/S0304423898000879>. Acesso em: $02 \mathrm{dez}$. 2012. doi: 10.1016/S0304-4238(98)00087-9.

FORCADA, C.F. et al. Agronomical and fruit quality traits of two peach cultivars on peach-almond hybrid rootstocks growing on Mediterranean conditions. Scientia Horticulturae, v.140, p.157-163, 2012. Disponível em: <http://www.sciencedirect.com/ science/article/pii/S0304423812001732>. Acesso em: $02 \mathrm{dez}$. 2012. doi: 10.1016/j.scienta.2012.04.007. 
GANJEWALA, D. et al. Advances in cyanogenic glycosides biosynthesis and analyses in plants: A review. Acta Biologica Szegedienis, v.54, n.1, p.1-14, 2010. Disponível em: <http://www2. sci.u-szeged.hu/ABS/2010/HP/5401.pdf>. Acesso em: 10 fev. 2013.

GAO, S. et al. Effects of salt stress on growth, antioxidant enzyme and phenylalanine ammonia-lyase activities in Jatropha curcas L. seedlings. Plant Soil and Environment, v.54, p.374381, 2008. Disponível em: <http://www.agriculturejournals.cz/ publicFiles/02069.pdf>. Acesso em: $10 \mathrm{dez} .2011$.

GJAMOVSKI, V.; KIPRIJANOVSKI, M. Influence of nine dwarfing apple rootstocks on vigour and productivity of apple cultivar 'Granny Smith'. Scientia Horticulturae, v.129, n.4, p.742-746, 2011. Disponível em: <http://www.sciencedirect.com/ science/article/pii/S0304423811002792>. Acesso em: $02 \mathrm{dez}$. 2012. doi: $10.1016 /$ j.scienta.2011.05.032

GUR, A.; BLUM, A. The role of cyanogenic glycoside in incompatibility between peach scions and almond rootstocks. Horticultural Research, v.13, p.1-10, 1973.

HARTMANN, H.T. et al. Plant propagation: principles and practices. New Jersey: Prentice Hall, 2010. 915p.

HERRERO, J. Incompatibilidad entre patron-variedad. III. Comparación de síntomas producidos por incompatibilidad y por el anillado del tronco. Anales de La Estación Experimental de Aula Dei, v.4, p.262-264, 1956

HURR, B.M. et al. Ethylene-induced overproduction of reactive oxygen species is responsible for the development of watersoaking in immature cucumber fruit. Journal of Plant Physiology, v.170, n.1, p.56-62, 2013. Disponível em: <http://www.sciencedirect. com/science/article/pii/S0176161712003549>. Acesso em: 02 fev. 2012. doi: 10.1016/j.jplph.2012.08.011.

HUSSAIN, S. et al. Performance evaluation of common clementine on various citrus rootstocks. Scientia Horticulturae, v.150, p.278-282, 2013. Disponível em: <http://www.sciencedirect.com/ science/article/pii/S0304423812005353>. Acesso em: $02 \mathrm{fev}$ 2013. doi: 10.1016/j.scienta.2012.11.010.

IAKIMOVA, E.T. et al. Morphological and biochemical characterization of Erwinia amylovora-induced hypersensitive cell death in apple leaves. Plant Physiology and Biochemistry, v.63, p.292-305, 2013. Disponínvel em: <http://www.sciencedirect. com/science/article/pii/S0981942812003531>. Acesso em: $02 \mathrm{dez}$. 2012. doi: 10.1016/j.plaphy.2012.12.006.

IVANCHENKO, M.G. et al. Ethylene-auxin interactions regulate lateral root initiation and emergence in Arabidopsis thaliana. Plant Journal, v.55, p.335-347, 2008. Disponível em: <http:// onlinelibrary.wiley.com/doi/10.1111/j.1365-313X.2008.03528.x/ pdf>. Acesso em: 20 jan. 2013. doi: 10.1111/j.1365313X.2008.03528.x.

KOLLMANN, R. et al. Studies on graft unions. Continuous and half plasmodesmata in different regions of the graft interface. Protoplasma, v.126, p.19-29, 1995

MARTÍNEZ-BALLESTA, M.C. et al. Physiological aspects of rootstock-scion interactions. Scientia Horticulturae, v.127, n.2, p.112-118, 2010. Acesso em: 02 dez. 2012. Disponível em: $<$ http:// www.sciencedirect.com/science/article/pii/S0304423810003687>. doi: 10.1016/j.scienta.2010.08.002.
MNG'OMBA, S.A. et al. The relationship between graft incompatibility and phenols in Uapaca kirkiana Müell Arg. Scientia Horticulturae, v.117, p.212-218, 2008. Disponível em: <http:// www.sciencedirect.com/science/article/pii/S0304423808001003>. Acesso em: 02 fev. 2012. doi: 10.1016/j.scienta.2008.03.031.

MOGHADAM, A.R.L. et al. Effect of indole butyric acid on micrografting of cactos. African Journal of Biotechnology, v.11, n.24, p.6484-6493, 2012. Disponível em: $<\mathrm{http}$ ://academicjournals. org/journal/AJB/article-abstract/BB450A339458>. Acesso em: 20 dez. 2012. doi: 10.5897/AJB11.2672.

MOING, A. et al. Growth and the composition and transport of carbohydrate in compatible and incompatible peach plum grafts. Tree Physiology, v.3, n.4, p.345-353, 1987. Disponível em: $<$ http://treephys.oxfordjournals.org/content/3/4/345.long $>$. Acesso em: 02 dez. 2012. doi: 10.1093/treephys/3.4.345.

MOORE, R. Graft incompatibility between pear and quince: the influence of metabolites of Cydonia oblonga on suspension cultures of Pyrus communis. American Journal of Botany, v.73, n.1, p.1-4, 1986.

MORENO, M. A. et al. Peach/myrabolan plum graft incompatibility in the nursey. Journal of Horticultural Science, v.68, p.705-714, 1993.

MOSSE, B. Further observation on growth and union structure of double grafted pear on quince. Journal of Horticultural Science, v.33, p.186-193, 1958.

MOSSE, B. Graft incompatibility in fruit trees. East Malling, England: Commerce of Bureau Horticultural Plant Crops, 1962. 36p. (Technical Communication 28).

MUDAY, G.K. et al. Auxin and ethylene: collaborators or competitors? Trends in Plant Science, v.17, n.4, p.181-195, 2012. Disponível em: <http://www.sciencedirect.com/science/article/pii/ S1360138512000295>. Acesso em: 02 fev. 2013. doi: 10.1016/j. tplants.2012.02.001.

MULLINEAUX, P.M.; BAKER, N.R. Oxidative stress: antagonistic signaling for acclimation or cell death? Plant Physiology, v.154, p.521-525, 2010. Disponível em: $<$ http://www. plantphysiol.org/content/154/2/521.full.pdf + html $>$. Acesso em: 02 dez. 2012. doi: 10.1104/pp.110.161406.

NOCITO, F.F. et al. Oxidative stress and senescence-like status of pear calli co-cultured on suspensions of incompatible quince microcalli. Tree Physiology, v.30, p.450-458, 2010. Disponível em: <http://treephys.oxfordjournals.org/content/30/4/450.long > Acesso em: 02 dez. 2012. doi: doi:10.1093/treephys/tpq006.

ORAZEM, P. et al. Quality analysis of 'Redhaven' peach fruit grafted on 11 rootstocks of different genetic origin in a replant soil. Food Chemistry, v.124, n.4, p.1691-1698, 2011. Disponível em: $<$ http://www.sciencedirect.com/science/article/pii/ S0308814610009313 >. Acesso em: 02 dez. 2012. doi: 10.1016/j. foodchem.2010.07.078

PEREIRA, I.S. Incompatibilidade de enxertia em Prunus, alterações fenotípicas, bioquímicas e gênicas. 2012. 160f. Tese (Doutorado em Fruticultura de Clima Temperado) - Faculdade de Agronomia Eliseu Maciel, Universidade Federal de Pelotas, RS.

PEREIRA, I.S. et al. Expression of the 4-coumarate:coa ligase gene family in compatible and incompatible prunus grafts. Acta Horticulturae, v.976, p.333-338, 2013. 
PINA A. et al. Cell-to-cell transport through plasmodesmata in tree callus cultures. Tree Physiology, v.29, p.809-818, 2009. Disponível em: <http://treephys.oxfordjournals.org/content/29/6/809.long >. Acesso em: 02 jan. 2011. doi: 10.1093/treephys/tpp025.

PINA, A.; ERREA, P. A review of new advances in mechanism of graft compatibility-incompatibility. Scientia Horticulturae, v.106, p.1-11, 2005. Disponível em: <http://www.sciencedirect. com/science/article/pii/S0304423805001561>. Acesso em: $02 \mathrm{dez}$. 2012. doi: 10.1016/j.scienta.2005.04.003.

PINA, A.; ERREA, P. Differential induction of phenylalanine ammonia-lyase gene expression in response to in vitro callus unions of Prunus spp. Journal of Plant Physiology, v.165, p.705-714, 2008. Acesso em: 02 dez. 2012. doi: 10.1016/j.jplph.2007.05.015.

PINA, A.; ERREA, P. Morphological and histochemical features of compatible and incompatible stem unions. Acta Horticulturae, v.814, p.453-456, 2009.

PINA,A. etal. Graft union formation and cell-to-cell communication via plasmodesmata in compatible and incompatible stem unions of Prunus spp. Scientia Horticulturae, v.143, p.144-150, 2012. Acesso em: 02 dez. 2012. doi: 10.1016/j.scienta.2012.06.017.

RODRIGUES, A.C. et al. Peroxidases e fenóis totais em tecidos de porta-enxertos de Prunus sp. Nos períodos de crescimento vegetativo e de dormência. Ciência Rural, v.4, p.559-564, 2002. Disponível em: <http://www.scielo.br/pdf/cr/v32n4/ a02v32n4.pdf $>$. Acesso em: 11 dez. 2010. doi: 10.1590/S010384782002000400002 .

SÁNCHEZ-PÉREZ, R. et al. Prunasin hydrolases during fruit development in sweet and bitter almonds. Plant Physiology, v.158, p.1916-1932, 2012. Disponível em: <http://www.plantphysiology. org/content/158/4/1916.full.pdf + html $>$. Acesso em: 02 dez. 2012. doi: $10.1104 /$ pp.111.192021.

SCARAMUZZI, F. Alcuni aspetti dei rapporti fra virosi e disaffinità d'innesto in frutticoltura. Notiziario Sulle Malattie delle Piante, v.47, n.48, p.75-102, 1959.

SINGH, O.P. et al. Enzymatic reactive oxygen species (ROS) scavenging system in mango varieties resistant and susceptible to malformation. Scientia Horticulturae, v.138, p81-89, 2012. Acesso em: 02 dez. 2012. doi: 10.1016/j.scienta.2011.12.031.

TELLES, C.A. et al. Fenóis totais, peroxidase e suas relações com a compatibilidade de mudas de pessegueiro interenxertadas. Ciência e Agrotecnologia, v.33, n.1, p.86-91, 2009. Disponível em: $<$ http://www.scielo.br/pdf/cagro/v33n1/v33n1a12.pdf $>$. Acesso em: 25 maio, 2010. doi: 10.1590/S1413-70542009000100012.

TOMBESI, S. et al. Phenotyping vigour control capacity of new peach rootstocks by xylem vessel analysis. Scientia Horticulturae, v.127, n3, p.353-357, 2011. Disponível em: <http://www. sciencedirect.com/science/article/pii/S030442381000511X $>$. Acesso em: 02 dez. 2012. doi: 10.1016/j.scienta.2010.11.007.

VETTER, J. Plant cyanogenic glycosides. Toxicon, v.38, p.1136, 2000. Disponível em: <http://www.sciencedirect.com/science/ article/pii/S0041010199001282>. Acesso em: 25 maio, 2010. doi: 10.1016/S0041-0101(99)00128-2.

WANG, S. et al. Influence of drought stress on the cellular ultrastructure and antioxidant system in leaves of drought-tolerant and drought-sensitive apple rootstocks. Plant Physiology and Biochemistry, v.51, p.81-89, 2012. Disponível em: <http://www. sciencedirect.com/science/article/pii/S0981942811003172>. Acesso em: 20 dez. 2012. doi: 10.1016/j.plaphy.2011.10.014.

YI, H. et al. Structure of soybean $\beta$-cyanoalanine synthase and the molecular basis for cyanide detoxification in plants. Plant and Cell Physiology, v.24, n.6, p.2696-2706, 2012. Disponível em: $<$ http://www.plantcell.org/content/24/6/2696.long $>$. Acesso em: 10 jan. 2013. doi: $10.1105 /$ tpc. 112.098954 .

YUAN, K. et al. Proteome analysis of interaction between rootstocks and scions in Hevea brasiliensis. African Journal of Biotechnology, v.10, n.66, p.14816-14825, 2011. Disponível em: <http://www.academicjournals.org/ajb/PDF/pdf2011/26Oct/ Yuan\%20et\%20al\%201.pdf>. Acesso em: 02 fev. 2012. doi: 10.5897/AJB11.1844.

ZARROUK, O. et al. Changes in cell/tissue organization and peroxidase activity as markers for early detection of graft incompatibility in peach/plum combinations. Journal of the American Society for Horticultural Science, v.135, p.9-17, 2010. Disponível em: <http://journal.ashspublications.org/ content/135/1/9.full>. Acesso em: 20 nov. 2012. 